\title{
Synthesis of Three-Dimensionally Interconnected Hexagonal Boron Nitride Networked Cu-Ni Composite
}

\author{
Zahid Hussain ${ }^{1}$, Hye-Won Yang ${ }^{1}$, and Byung-Sang Choi ${ }^{1,2, *}$ \\ ${ }^{1}$ Chosun University, Department of Advanced Materials Engineering, Gwangju 61452, Republic of Korea \\ ${ }^{2}$ Micro \& Nano Technologies, Inc., Gwangju 61452, Republic of Korea
}

\begin{abstract}
A three-dimensionally interconnected hexagonal boron nitride (3Di-hBN) networked $\mathrm{Cu}-\mathrm{Ni}$ (3DihBN-Cu-Ni) composite was successfully synthesized in situ using a simple two-step process which involved the compaction of mixed $\mathrm{Cu}-\mathrm{Ni}$ powders $(70 \mathrm{wt} . \% \mathrm{Cu}$ and $30 \mathrm{wt} . \% \mathrm{Ni}$ ) into a disc followed by metal-organic chemical vapor deposition (MOCVD) at $1000^{\circ} \mathrm{C}$. During MOCVD, the $\mathrm{Cu}-\mathrm{Ni}$ alloy grains acted as a template for the growth of hexagonal boron nitride $(\mathrm{hBN})$ while decaborane and ammonia were used as precursors for boron and nitrogen, respectively. Boron and nitrogen atoms diffused into the $\mathrm{Cu}-\mathrm{Ni}$ solution during the MOCVD process and precipitated out along the $\mathrm{Cu}$-Ni interfaces upon cooling, resulting in the formation of the 3Di hBN-Cu-Ni composite. Energy-dispersive spectroscopic analysis confirmed the presence of boron and nitrogen atoms at the interfaces of $\mathrm{Cu}-\mathrm{Ni}$ alloy grains. Optical microscopy examination indicated that there was a minimum amount of bulk $\mathrm{hBN}$ at a certain compaction pressure (280 MPa) and sintering time (30 min). Scanning electron microscopy and transmission electron microscopy revealed that an interconnected network of hBN layers surrounding the $\mathrm{Cu}-\mathrm{Ni}$ grains developed in the 3Di-hBN-Cu-Ni composite. This 3Di-hBN network is expected to enhance the mechanical, thermal, and chemical properties of the 3Di-hBN-Cu-Ni composite. Moreover, the foam-like 3Di-hBN extracted from 3Di-hBN-Cu-Ni composite could have further applications in the fields of biomedicine and energy storage.
\end{abstract}

(Received March 15, 2021; Accepted April 7, 2021)

Keywords: hexagonal boron nitride, reinforcement, 3Di-hBN-Cu-Ni composite, MOCVD

\section{Introduction}

The development of two-dimensional (2D) materials has opened up the possibilities for their application to improve the properties of metals and alloys [1-8], because 2D materials have the ability to alter the properties of metals at the nanoscale. A single layer of hexagonal boron nitride (hBN) is structurally similar to graphene (carbon system) with the hexagonal lattices occupied by boron and nitrogen atoms. hBN has a lattice parameter of $25 \mathrm{~nm}$ and possesses extraordinary properties, including high chemical stability [9], high mechanical strength [9], low density [10], high thermal stability [11], and high thermal shock resistance [12]. These excellent properties can be utilized to improve the

\footnotetext{
-Zahid Hussain: 박사과정, 양혜원: 석사과정, 최병상: 교수

*Corresponding Author: Byung-Sang Choi

[Tel: +82-62-230-7190, E-mail: bschoi@chosun.ac.kr]

Copyright (c) The Korean Institute of Metals and Materials
}

performance of various metal matrix composites (MMCs) by constructing three-dimensionally interconnected (3Di) hBN layers in their grain boundaries. Similar approaches have been employed by other researchers, who have used 3Dnetworked graphene to tailor the properties of MMCs $[8,13-$ 15]. For instance, Chen et al. [13] enhanced the yield and tensile strengths of copper by wrapping graphene around copper grains using chemical vapor deposition (CVD). They reported that the graphene acted as a barrier to dislocation movement, and consequently, the elastic modulus and strength were improved. $\mathrm{Li}$ et al. [8] reported that $\mathrm{Cu}$-graphene composites had a higher thermal conductivity than pure copper because graphene offered an effective path for heat transfer between the $\mathrm{Cu}$ grain boundaries. Other properties, such as corrosion resistance and wear resistance, have also been improved [16,17].

Because of its structure similarity to graphene, introducing the $\mathrm{hBN}$ into metal matrices can result in similar effects. 
Several researchers have used boron nitride nanoparticles to enhance the strength, hardness, wear, and corrosion resistance of metallic alloys [18-22]. For instance, the microstructure and properties of BN/Ni-Cu composites fabricated by powder technology were reported by Tantaway et al. [23]. They found that the $\mathrm{BN}$ content led to a decrease in density and an increase in the hardness, electrical resistivity, and saturation magnetization of the composite. Omayma et al. [10] fabricated $\mathrm{Cu} / \mathrm{hBN}$ nanocomposites by the $\mathrm{PM}$ route, in which powder mixtures of $\mathrm{Cu}$ and $\mathrm{hBN}$ were compacted and sintered at various temperatures ranging from $950{ }^{\circ} \mathrm{C}$ to $1000^{\circ} \mathrm{C}$. They found that the physical, mechanical and tribological properties of the composite were influenced by the hBN. However, we have not found any published studies in which metal matrices were reinforced by a 3Di network of $\mathrm{hBN}$ layers.

Recently, various techniques have been utilized to fabricate reinforced MMCs by incorporating graphene. For instance, Xiong et al. [24] introduced graphene in $\mathrm{Cu}$ by the reduction of reduced graphene oxide through sintering. Similarly, ball milling, molecular-level synthesis, spark plasma sintering, and epitaxial growth have been used to improve the strength of composites, employing graphene as a reinforcement [13, 25-28]. However, each of the these strengthening techniques has some limitations. For instance, ball milling and molecularlevel mixing may allow a uniform dispersion of the reinforcement material but may impart structural defects due to shear stress and contamination during the fabrication process [29]. A well-ordered/-aligned, uniformly dispersed, and continuous graphene network is essential to attain the best reinforcement results [13]. Kawk et al. [30] introduced a simple, economically efficient two-step process with the potential to deliver better-quality products with uniformly dispersed and continuous graphene networks.

The two-step process involves the compaction of a metallic powder followed by CVD. In this study, we fabricated a 3DihBN-Cu-Ni composite using a similar simple two-step process. Various characterization techniques were employed to confirm the formation of $3 \mathrm{Di}-\mathrm{hBN}$ surrounding the grains of the $\mathrm{Cu}-\mathrm{Ni}$ alloys. $\mathrm{Cu}-\mathrm{Ni}$-based alloys have been employed in various industries, including shipbuilding, construction, and processing, because of their high mechanical strength and corrosion resistance at elevated temperatures. The $3 \mathrm{Di}-$ $\mathrm{hBN}-\mathrm{Cu}-\mathrm{Ni}$ composite is expected to deliver better corrosion, mechanical, and wear characteristics than the $\mathrm{Cu}-\mathrm{Ni}$ alloy. Moreover, the 3Di-hBN, which has a foam-like 3D porous structure, was separated from the 3Di-hBN-Cu-Ni composite and could have further applications in the fields of biomedicine, electronics, and energy storage [31-33].

\section{Experimental Procedures}

\subsection{Fabrication of 3Di-hBN-Cu-Ni Composite}

$\mathrm{Cu}$ powder ( $99.5 \%$ purity) with spheroidal particles of size 14-25 $\mu \mathrm{m}$ and Ni powder ( $>99.5 \%$ purity) with spheroidal particles of size $\sim 1 \mu \mathrm{m}$ were purchased from Sigma-Aldrich and used after heat treatment $\left(200^{\circ} \mathrm{C}\right.$ for $2 \mathrm{~h}$ in an $\mathrm{H}_{2}$ environment) to remove any moisture or oxide contents. The chemical compositions of $\mathrm{Cu}$ and Ni powders are provided in Table 1. $\mathrm{Cu}$ and Ni powders (70 wt.\% Cu, 30 wt.\% Ni) were mixed manually using mortar, while taking care not to change the particle size distribution. The mixture was compacted in a mold using a double-action oil hydraulic press at compaction pressures of $60,110,220,280,335$, and $390 \mathrm{MPa}$. The exertion of high pressure on the spheroidal particles caused mechanical cold locking among the particles, forming a compact disc with the approximate diameter and thickness of $15 \mathrm{~mm}$ and $1.2 \mathrm{~mm}$, respectively. As shown on the fracture surface of the cross section of the compact disc in Figure 1, the relatively large $\mathrm{Cu}$ particles induced mechanical interlocking, due to their deformation, and $\mathrm{Ni}$ particles filled the gaps between the $\mathrm{Cu}$ particles. The discs were then placed in a quartz glass tube furnace with a tube diameter of $23 \mathrm{~mm}$ for metal-organic CVD (MOCVD). The compaction pressure and sintering time were varied to determine the optimum conditions for the fabrication of 3D-

Table 1. Chemical compositions of $\mathrm{Cu}$ and Ni powders.

\begin{tabular}{|c|c|c|}
\hline Material & Purity & Trace metals in ppm \\
\hline Cu Powder & $>99.5 \%$ & $\mathrm{Fe}$ 80.0, $\mathrm{Na} 9.42, \mathrm{Mn} 7.6, \mathrm{Mg} 4.69, \mathrm{Al} 4.4$, and $\mathrm{B} 1.98$ \\
\hline Ni Powder & $>99.5 \%$ & $\begin{array}{c}\mathrm{Ag} \mathrm{1.3,} \mathrm{Al17.9,} \mathrm{Ba} 0.8 \mathrm{Ca} 27.9, \mathrm{Cr} 3.6, \mathrm{Cu} 305.2, \mathrm{Fe} 383.7 \mathrm{Mg} 2.0, \mathrm{Mn} 2.6 \text {, } \\
\mathrm{Na} 11.1, \mathrm{Pd} 8.0 \text {, Ti 144.5, and V } 25.4\end{array}$ \\
\hline
\end{tabular}




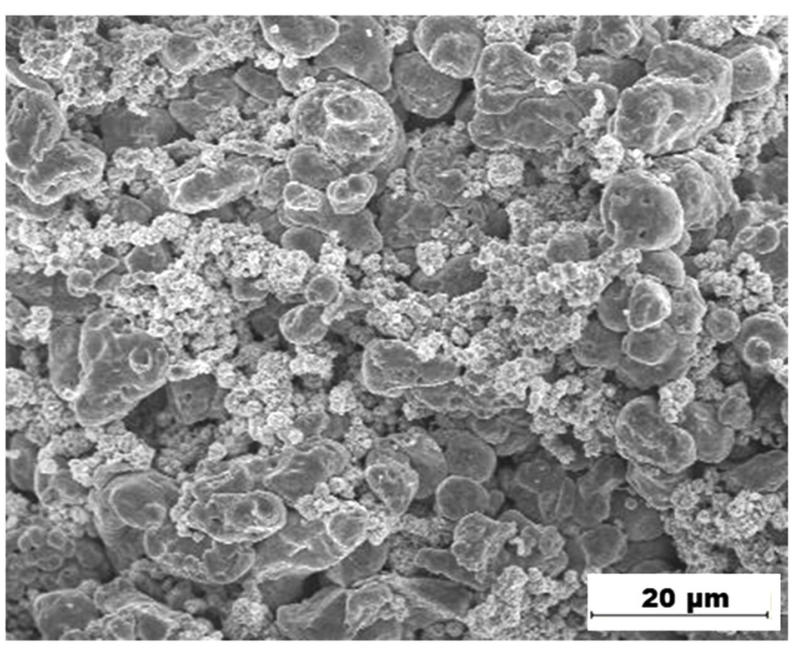

Fig. 1. $\mathrm{Cu}$ and Ni particles shown at the fracture surface of the disc after compaction.

$\mathrm{hBN}$ in the 3Di-hBN-Cu-Ni composite.

Figure 2 (a) shows a schematic of the system used to fabricate the 3Di-hBN-Cu-Ni composites. First, the system was flushed with argon at least three times to remove air from the MOCVD tube. The furnace temperature was increased to $400{ }^{\circ} \mathrm{C}$ at a rate of $16.6^{\circ} \mathrm{C} / \mathrm{min}$ and then maintained constant in a hydrogen environment at 330 Torr for $1 \mathrm{~h}$ for deoxidation. Subsequently, the temperature was raised to $1000{ }^{\circ} \mathrm{C}$ at the same rate and maintained constant for 15 or $30 \mathrm{~min}$.
Finally, MOCVD was performed for $15 \mathrm{~min}$ at 450 Torr using heated decaborane $\left(\mathrm{B}_{10} \mathrm{H}_{14}\right)$ as the boron source and ammonia $\left(\mathrm{NH}_{3}\right)$ as the nitrogen source. Decaborane was the preferred boron precursor because of its (i) easy handling, (ii) commercial availability, and (iii) stability, which minimized the formation of undesired side products at elevated temperatures that could potentially decrease hBN yield [34]. Decaborane is a crystalline solid with a melting temperature of $98-100{ }^{\circ} \mathrm{C}$ and its vapor pressure can be easily controlled by varying the temperature from room temperature to $100^{\circ} \mathrm{C}$. At approximately $100{ }^{\circ} \mathrm{C}$, the vapors produced upon evaporation can be transported into the MOCVD growth zone by an inert carrier gas (Ar) at a flow rate of $1 \mathrm{sccm}$. Ammonia gas was introduced as a nitrogen source in the MOCVD reaction zone at a flow rate of $2 \mathrm{sccm}$. At $1000^{\circ} \mathrm{C}$, ammonia and decaborane dissociated into nitrogen and boron atoms, respectively.

$$
\begin{aligned}
& N_{3(g)} \rightarrow[N]+\frac{3}{2} H_{2(g)}, \\
& B_{10} H_{14(g)} \rightarrow 10[B]+7 H_{2(g)}
\end{aligned}
$$

The entire process (heating, sintering, and MOCVD) was conducted at a hydrogen flow rate of $10 \mathrm{sccm}$. The $3 \mathrm{Di}-\mathrm{hBN}-$ $\mathrm{Cu}-\mathrm{Ni}$ composite, fabricated using the simple two-step

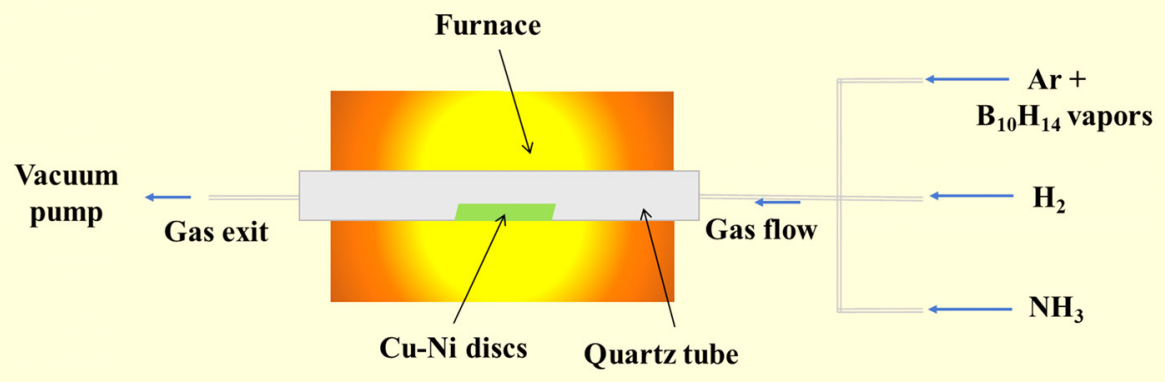

(a)

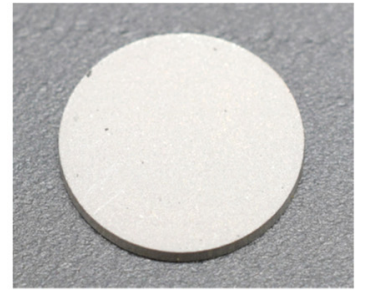

(b)

Fig. 2. (a) Schematic illustration of the fabrication of 3Di-hBN-Cu-Ni composite and (b) disc-shaped 3Di-hBN-Cu-Ni composite fabricated using a simple two-step process. 


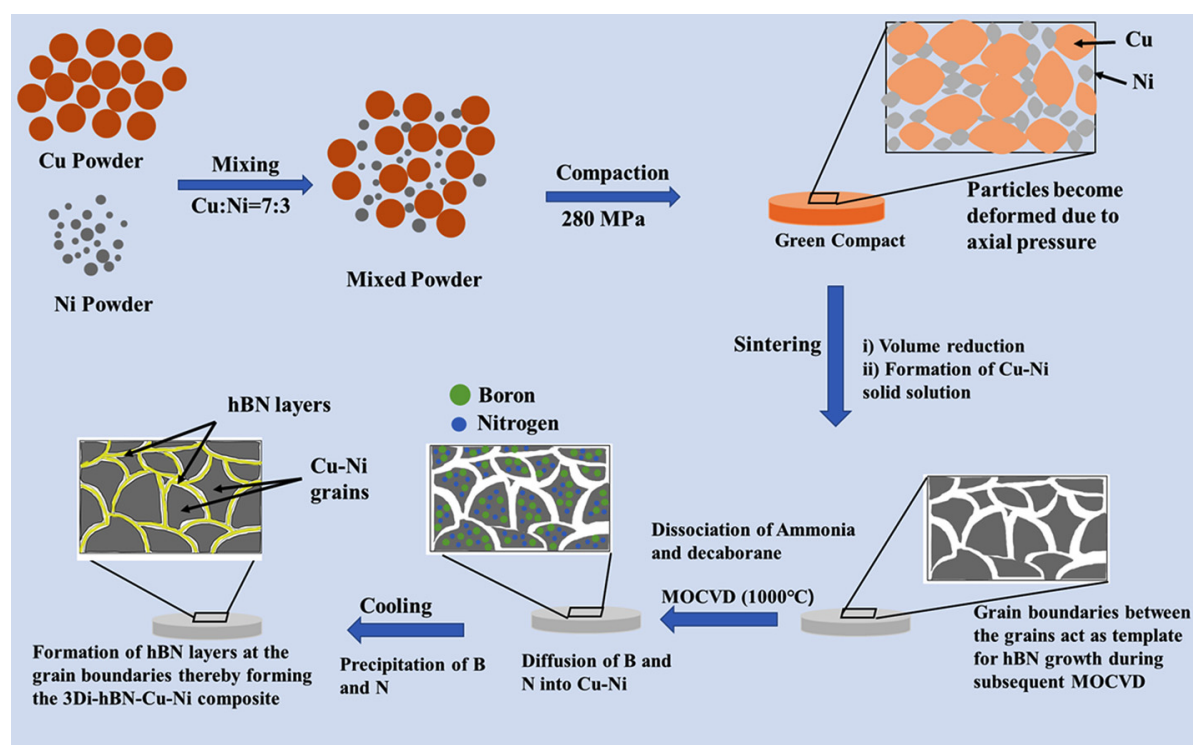

Fig. 3. Schematic showing the process of formation of $3 \mathrm{Di}-\mathrm{hBN}-\mathrm{Cu}-\mathrm{Ni}$ composite.

process, is shown in Figure 2(b).

\subsection{Characterization}

Optical microscopy (OM) and scanning electron microscopy (SEM) investigations of the 3Di-hBN-Cu-Ni composite samples were conducted after the sample was cut in half and the cutting surface was polished with emery papers down to 4000 grit. Finally, the polished surface was etched at room temperature using a mixed solution of $1 \mathrm{M} \mathrm{FeCl}_{3}$ and $0.1 \mathrm{M}$ $\mathrm{HCl}$ to reveal the microstructure [30]. For transmission electron microscopy (TEM) investigations, the 3Di-hBN-Cu$\mathrm{Ni}$ composite samples were mechanically polished to a thickness of $100 \mu \mathrm{m}$ and cut into small pieces of $3 \mathrm{~mm}$ diameter. Then, the $\mathrm{Cu}-\mathrm{Ni}$ was etched out, leaving only 3Di$\mathrm{hBN}$ foam, which was transferred after thorough cleaning to the TEM grid for investigation. A qualitative phase analysis of the 3Di-hBN-Cu-Ni composite was performed by XRD analysis using $\mathrm{Cu} \mathrm{K}_{\alpha}$ radiation with a wavelength of $1.54 \AA$ and a scanning angle of $20^{\circ}-100^{\circ}$. The density of the 3DihBN-Cu-Ni composite samples was measured using the Archimedes immersion technique.

\subsection{Three-Dimensionally Interconnected hBN}

The 3Di-hBN-Cu-Ni composite samples were cut into small pieces, polished, and placed in an etchant for a sufficient duration to etch out $\mathrm{Cu}-\mathrm{Ni}$ completely, so that only
3Di-hBN remained. Then, the foam-like 3Di-hBN samples were removed and washed several times with deionized water. To obtain a stable $3 \mathrm{D}$ structure of the $3 \mathrm{Di}-\mathrm{hBN}$, the freeze-drying method was used to ensure that there was no effect of liquid capillary force, and that the 3Di-hBN did not structurally collapse [35].

\section{Results and Discussions}

Figure 3 shows a schematic of the processes involved in the synthesis of the 3Di-hBN-Cu-Ni composite. During the sintering, a reduction in volume and the formation of a $\mathrm{Cu}$ Ni solid solution occur due to the diffusion of metals under the driving force, to reduce the excess surface energy [36, 37]. Consequently, the overall volume of the compact disc is reduced and densification occurs. The formation of $3 \mathrm{Di}-\mathrm{hBN}$ in the composite is likely to occur in three stages [8]. First, the diffusion of metal occurs to reduce the surface energy, resulting in the formation of large particles (consolidation). At the same time, the diffusion of $\mathrm{Ni}$ to $\mathrm{Cu}$ or vice versa occurs to form a solid solution of $\mathrm{Cu}-\mathrm{Ni}$. Next, during the MOCVD process, the dissociation of ammonia and decaborane produces nitrogen and boron atoms that diffuse into the $\mathrm{Cu}-\mathrm{Ni}$ alloy at $1000{ }^{\circ} \mathrm{C}$. Finally, upon cooling, the nitrogen and boron atoms precipitate out and alternately join together to form $2 \mathrm{D} \mathrm{hBN}$ layer(s) along the interfaces of the 


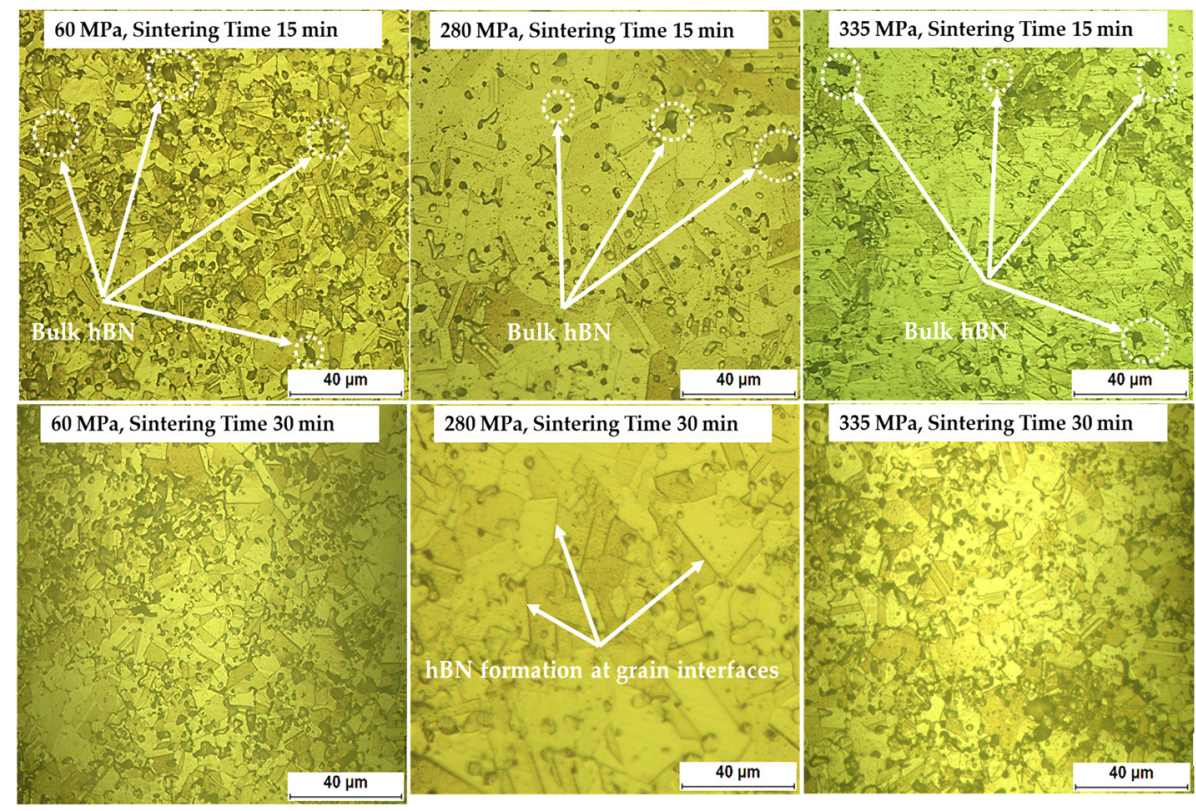

Fig. 4. OM images of 3Di-hBN-Cu-Ni composites under various conditions.

$\mathrm{Cu}-\mathrm{Ni}$ grains [38] resulting in the formation of the $\mathrm{Cu}-\mathrm{Ni}$ composite.

Small pores or voids can form during the sintering, as $\mathrm{Cu}$ and Ni particles grow to reduce their surface energy. This is probably due to insufficient sintering time or excessive free space among the particles. These pores may also act as catalytic sites for the nucleation and growth of bulk hBN. The small lighter grey areas (indicated by small white loops) in Figure 4 indicate the bulk hBN that accumulated on the pores during the MOCVD process. These pores, generated during the sintering process and then filled with bulk hBN during the MOCVD process, are undesirable, as they may adversely affect the mechanical, thermal, and wear characteristics of the composite. Therefore, the processing parameters, such as compaction pressure and sintering time, must be varied to determine the optimal conditions for fabricating 3Di-hBN-Cu$\mathrm{Ni}$ composites without the formation of bulk hBN.

Figure 5 shows the density of the 3Di-hBN-Cu-Ni composite as a function of the compaction pressure and sintering time. The density of the composite increased with increasing compaction pressure. However, beyond a certain compaction pressure, the density decreased. This trend occurred because at pressures below $280 \mathrm{MPa}$, the compaction pressure was not enough, resulting in a low density of compaction. This

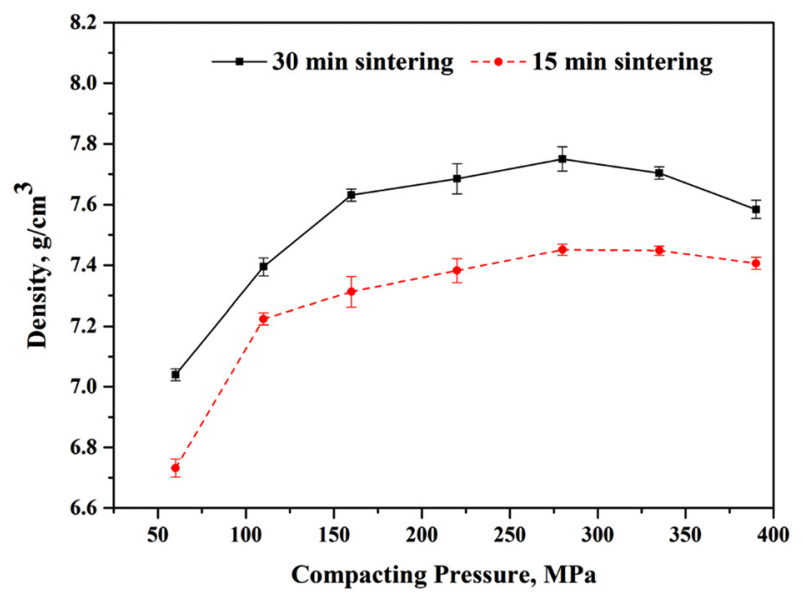

Fig. 5. Density of the 3Di-hBN-Cu-Ni composite as a function of compacting pressure and sintering time.

consequently resulted in a lower density composite with voids or pores. Although these pores were filled with bulk $\mathrm{hBN}$ during the subsequent MOCVD process, the overall density of the composite could not be increased because the density of $\mathrm{hBN}\left(2.1 \mathrm{~g} / \mathrm{cm}^{3}\right)$ is significantly lower than that of $\mathrm{Cu}-$ $\mathrm{Ni}\left(\sim 8.9 \mathrm{~g} / \mathrm{cm}^{3}\right)$. On the other hand, during compaction at high pressures $(>280 \mathrm{MPa})$, the particles on the surface were pressed with a relatively greater force than those inside the compact disc, because of friction between the particles. Consequently, at pressures exceeding $280 \mathrm{MPa}$, the surface 


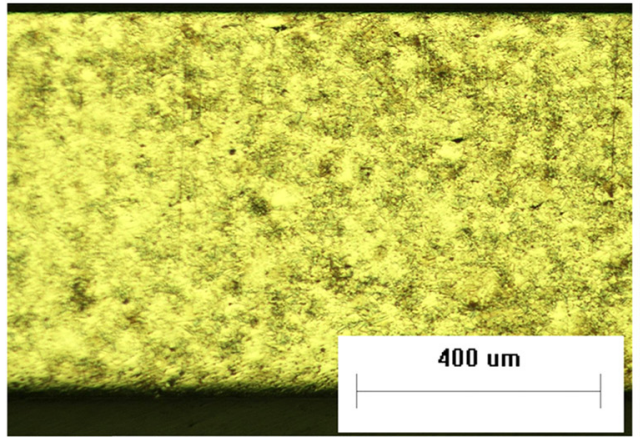

(a)

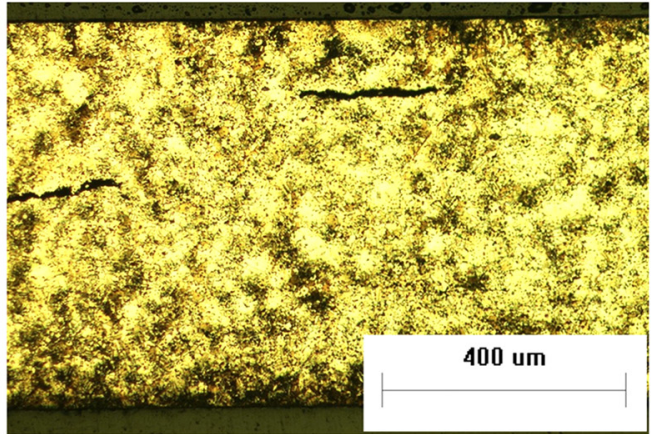

(b)

Fig. 6. OM images of 3Di hBN-Cu-Ni composites processed at compaction pressures of (a) $280 \mathrm{MPa}$ and (b) $335 \mathrm{MPa}$.

particles of the compact disc were denser than the inner particles. The inner particles, having a longer diffusion distance owing to their lower density, resulted in the formation of pores due to insufficient diffusion or short sintering time. This led to the relatively larger size of pores, or shrinkage, as indicated in the OM images in Figure 6(b). Hence, the density of the 3Di-hBN-Cu-Ni composite was slightly lower at higher pressures $(>280 \mathrm{MPa})$, as shown in Figure 5 . This is also evident in the OM images shown in Figure 4. The white arrows in Figure 4 indicate the bulk hBN present in the microstructure of the $3 \mathrm{Di}-\mathrm{hBN}-\mathrm{Cu}-\mathrm{Ni}$ composite. A relatively higher volume fraction of bulk $\mathrm{hBN}$ was observed when the compaction pressure was lower or higher than $280 \mathrm{MPa}$. Furthermore, the density of the 3Di-hBN-Cu-Ni composite also depends on the sintering time, as shown in Figure 5. A longer sintering time led to fewer pores (i.e., a lower volume fraction of bulk $\mathrm{hBN}$ ), and consequently more densification occurred.

The 3Di-hBN-Cu-Ni-hBN composite fabricated under the optimized conditions (a compaction pressure of $280 \mathrm{MPa}$ and a sintering time of $30 \mathrm{~min}$ ) was examined using SEM. While some of the bulk hBN was removed during the polishing and etching, the SEM image in Figure 7 and the EDS results in Table 2 show the $\mathrm{Cu}-\mathrm{Ni}$ grains, bulk hBN of less than $5 \mu \mathrm{m}$ in size, and $\mathrm{hBN}$ along the interfaces. The $\mathrm{Cu}-\mathrm{Ni}$ grains,

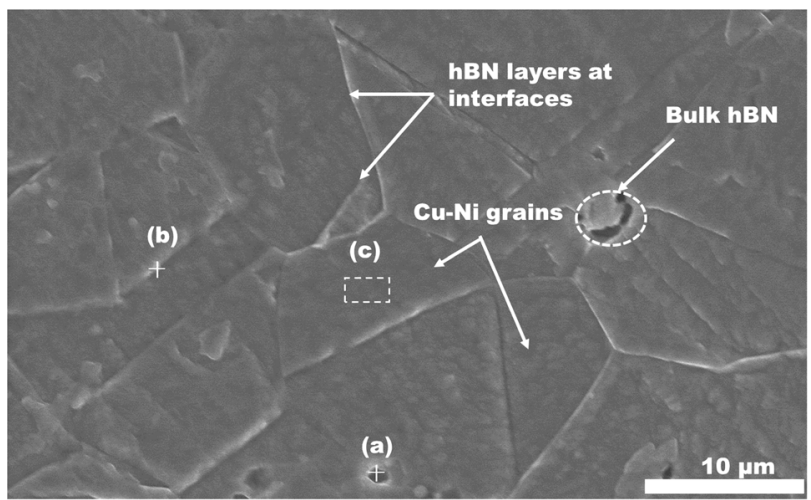

Fig. 7. SEM image showing the surface morphology of the 3Di$\mathrm{hBN}-\mathrm{Cu}-\mathrm{Ni}$ composite fabricated with compaction pressure of 280 $\mathrm{MPa}$ and sintering time of $30 \mathrm{~min}$.

grain boundaries, and bulk $\mathrm{hBN}$ in Figure 7 were analyzed using energy-dispersive X-ray spectroscopy (EDS). Boron and nitrogen were observed (locations (a) and (b) in Figure 7) in excess along with minute amounts of other impurities, such as silicon, carbon, and oxygen, as listed in Table 2. These impurities probably entered the structure during the polishing and etching processes. Location (a) in Figure 7 is a pore that was first formed as a consequence of sintering and then filled with bulk hBN during the subsequent MOCVD process. Considering the average size $(5 \mu \mathrm{m})$ of these sites (location (a)), the presence of bulk hBN was verified through

Table 2. EDS results of the 3Di-hBN-Cu-Ni composite for the microstructure shown in Figure 7.

\begin{tabular}{ccccccccc}
\hline Element & Location & Cu & Ni & B & N & Si & C & O \\
\hline At. \% & (a) in Figure 7 & - & - & 49.32 & 47.45 & 0.76 & 0.87 & 0.68 \\
At. \% & (b) in Figure 7 & 20.51 & 8.32 & 34.26 & 34.82 & 0.89 & 0.57 & 0.78 \\
At. \% & (c) in Figure 7 & 71.28 & 28.42 & - & - & - & - & - \\
\hline
\end{tabular}




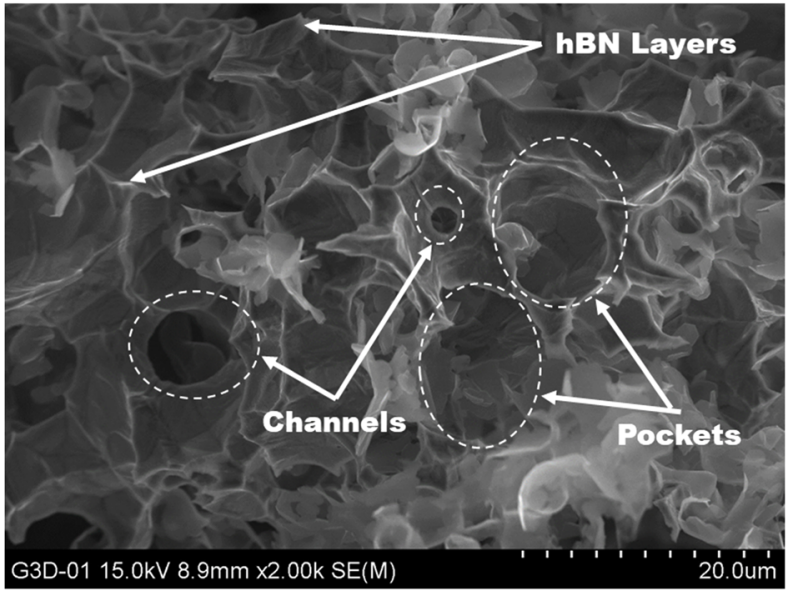

Fig. 8. SEM image showing the 3D interconnected network of hBN in $3 \mathrm{Di} \mathrm{hBN-Cu}-\mathrm{Ni}$ composite produced under compaction pressure of $280 \mathrm{MPa}$ and sintering time of $30 \mathrm{~min}$, respectively.

EDS analysis. Further EDS analysis at the grain boundaries (location (b)) revealed that the grain boundaries were also mostly occupied by boron and nitrogen with an approximate stochiometric ratio of $1: 1$. As expected, the $\mathrm{Cu}-\mathrm{Ni}$ grains (location (c) in Figure 7) comprised $\mathrm{Cu}$ and $\mathrm{Ni}$ atoms with a ratio of approximately 7 to 3 , as shown in Table 2 . The solubility of $\mathrm{B}$ and $\mathrm{N}$ in $\mathrm{Cu}-\mathrm{Ni}$ alloy at $1000{ }^{\circ} \mathrm{C}$ is very small $(\sim$ ppm) [23] and most of the atoms (B and N) precipitated out during cooling, thus forming $\mathrm{hBN}$ with $\mathrm{B}$ and $\mathrm{N}$ having a stochiometric ratio of 1:1 at the grain boundaries [39-41]

The SEM image in Figure 8 shows various hBN layers that interconnect to form a foam-like structure with pockets and channels. The channels are the connected areas between the
$\mathrm{Cu}-\mathrm{Ni}$ grains formed by etching. The average pocket size $(10-20 \mu \mathrm{m})$ in $3 \mathrm{Di}-\mathrm{hBN}$ (Figure 8 ) is approximately equal to the average grain size of the $3 \mathrm{Di}-\mathrm{hBN}-\mathrm{Cu}-\mathrm{Ni}$ composite (Figures 4 and 7) indicating that the hBN layers are wrapped around the $\mathrm{Cu}-\mathrm{Ni}$ grains in the 3Di-hBN-Cu-Ni composite.

The XRD pattern of the 3Di-hBN-Cu-Ni composite is shown in Figure 9(a). This pattern only shows the crystalline phase of $\mathrm{Cu}-\mathrm{Ni}$ solid solution. The elemental distribution map of the 3Di-hBN-Cu-Ni composite shown in Figure 9(b) shows a uniform distribution of $\mathrm{Cu}$ and $\mathrm{Ni}$, indicating the formation of a $\mathrm{Cu}-\mathrm{Ni}$ solid solution.

The 3Di-hBN foam was inspected using TEM. The lowmagnification bright-field TEM image in Figure 10(a) shows a complex morphology with curvatures and overlapped structures, where the 3D layers of hBN (shown in Figure 8) collapsed after their transfer to the TEM grid under the capillary force during the drying process. The selected-area electron diffraction pattern of 3Di-hBN (inset in Fig. 10(a)) indicates multiple orientations associated with a couple of layers with different orientations. The high-resolution TEM (HR-TEM) image (Figure10 (b)) reveals 2-6 layers of hBN, with an interlayer distance of approximately $0.25 \mathrm{~nm}$ (inset in Figure 10(b)), which is considered to be the thickness of a single layer of $2 \mathrm{D} \mathrm{hBN}$.

\section{Conclusion}

3Di-hBN-Cu-Ni composites were synthesized via a simple two-step process: (1) compacting $\mathrm{Cu}$ and $\mathrm{Ni}$ powder mixtures

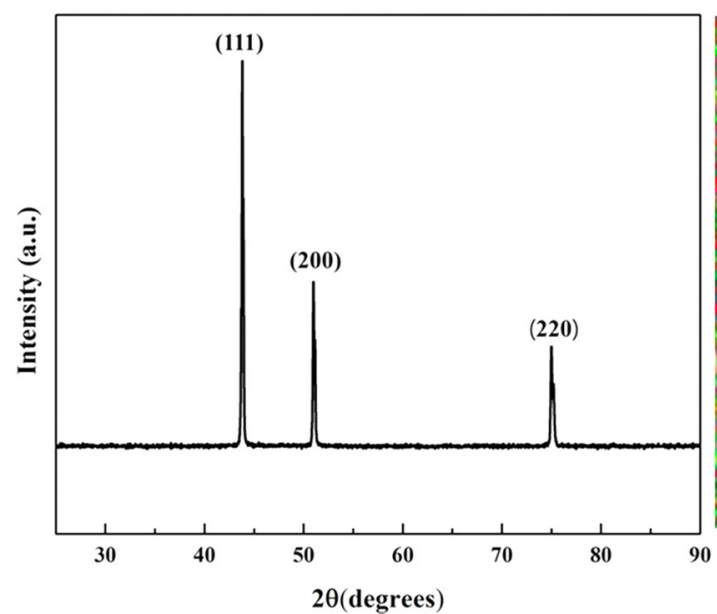

(a)

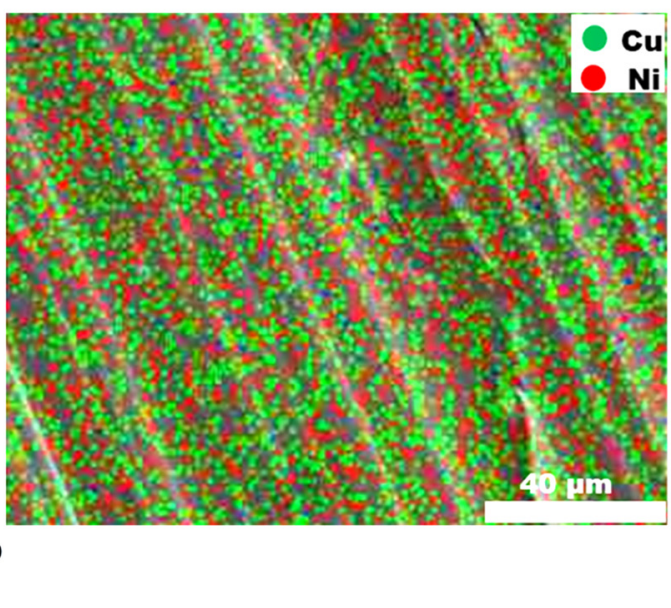

(b)

Fig. 9. (a) XRD pattern of 3Di-hBN-Cu-Ni composite and (b) Elemental distribution map of 3Di-hBN-Cu-Ni composite. 


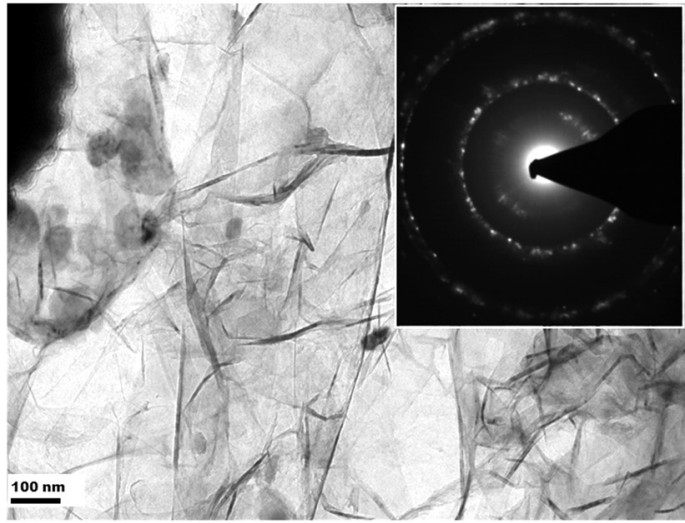

(a)

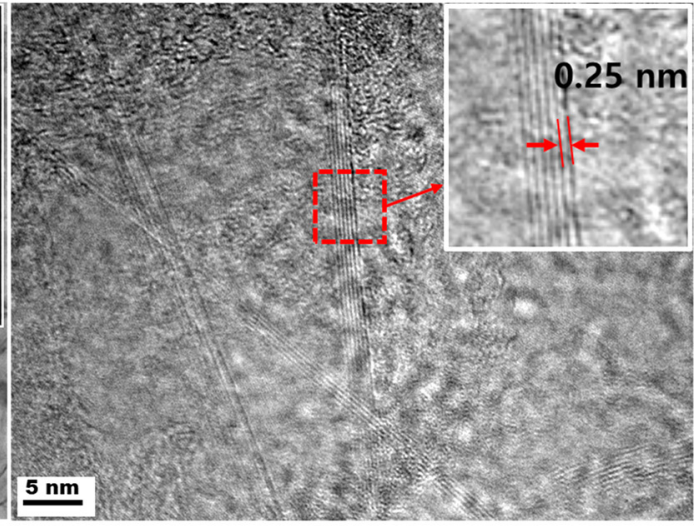

(b)

Fig. 10. TEM investigation: (a) low-magnification bright-field TEM image of 3Di-hBN and (b) HR-TEM image showing 2-6 layers of $\mathrm{hBN}$ (inset shows a distance of $0.25 \mathrm{~nm}$ between layers).

without any additives and (2) MOCVD. The density of the composite was the highest $\left(7.75 \mathrm{~g} / \mathrm{cm}^{3}\right)$ when the compaction pressure and sintering time were $280 \mathrm{MPa}$ and $30 \mathrm{~min}$, respectively. OM, SEM, and TEM images indicated that these conditions were optimal for the growth of interconnected network of hBN in the 3Di-hBN-Cu-Ni composite. SEM investigations and EDS analysis revealed that the grain boundaries were mostly occupied by boron and nitrogen atoms. 3Di-hBN was obtained after etching the $\mathrm{Cu}-\mathrm{Ni}$ alloy. The average pocket size of the foam was 10-20 $\mu \mathrm{m}$. The 3DihBN-Cu-Ni composite with a density of $7.75 \mathrm{~g} / \mathrm{cm}^{3}$ was shown to have a three-dimensional network of hBN. The structural investigation of 3Di-hBN using TEM revealed 2-6 layers with an interlayer distance of $0.25 \mathrm{~nm}$. This study can be extended further, with characterizations of the physical and chemical properties of the $3 \mathrm{Di}-\mathrm{hBN}-\mathrm{Cu}-\mathrm{Ni}$ composite and 3Di-hBN.

\section{ACKNOWLEDGEMENT}

This study was supported by research funds from Chosun University (2020).

\section{REFERENCES}

1. S. F. Bartolucci, J. Paras, M. A. Rafiee, J. Rafiee, S. Lee, D. Kapoor, and N. Koratkar, Mater. Sci. Eng. A 528, 7933 (2011).
2. K. Chu and C. Jia, Phys. Status Solidi A 211, 184 (2014).

3. S. Guo, X. Zhang, C. Shi, E. Liu, C. He, F. He, and N. Zhao, Mater. Sci. Eng. A 766, 138365 (2019).

4. Y. Liu, H. Wu, and G. Chen, Polym. Composite. 37,1190 (2016).

5. M. A. Rafiee, J. Rafiee, Z. Wang, H. Song, Z. Z. Yu, and N. Koratkar, ACS Nano 3, 3884 (2009).

6. W. Yang, Q. Zhao, L. Xin, J. Qiao, J. Zou, P. Shao, Z. Yu, Q. Zhang, and G. Wu, J. Alloy. Compd. 732, 748 (2018).

7. Y. Jo, X. Li, J. M. Jo, and B. S. Choi, J. Adv. Eng. and Tech. 12, 91 (2019).

8. X. Li, T. A. Ring, and B. S. Choi, Korean J. Met. Mater. 57, 529 (2019).

9. S. P. Singh, MSc Thesis, pp.54-55, Thapar Insitute of Technology, Patalia (2018).

10. A. M. Omayma, A. A. Oqail, M. M. Emad, and M. E. Sheikh, J. Alloy. Compd. 625, 309 (2015).

11. Z. Liu, Y. Gong, W. Zhou, L. Ma, J. Yu, J. C. Idrobo, J. Jung, A. H. MacDonald, R. Vajtai, J. Lou, and P. M. Ajayan, Nat. commun. 4, 1 (2013).

12. X. Duan, Z. Yang, L. Chen, Z. Tian, D. Cai, Y. Wang, D. Jia, and Y. Zhou, J. Eur. Ceram. Soc. 36, 3725 (2016).

13. Y. Chen, X. Zhang, E. Liu, C. He, Y. Han, Q. Li, P. Nash, and N. Zhao, J. Alloy. Compd. 688, 69 (2016).

14. S. E. Kim and I. J. Shon, Korean J. Met. Mater. 56, 854 (2018).

15. M. Y. Song, Y. J. Kwak, and E. Choi, Korean J. Met. Mater. 56, 524 (2018).

16. M. Wu, B. Hou, S. Shu, A. Li, Q. Geng, H. Li, Y. Shi, M. Yang, S. Du, J. Q. Wang, S. Liao, N. Jiang, D. Dai, and C. 
T. Lin, Nanomaterials 9, 498 (2019).

17. K. Tripathi, G. Gyawali, and S. W. Lee, ACS Appl. Mater. Inter. 9, 32336 (2017).

18. S. Gopinath, M. Prince, and G. Raghav, Mater. Res. Express 7, 016582 (2020).

19. A. C. Reddy, Proc. 5th International Conference on Modern Materials and Manufacturing, p.409, MMM, Banglore, India (2013).

20. E. Zitoun and A. C. Reddy, Proc. 6th National Conference on Materials and Manufacturing Processes, Hyderabad, India (2008).

21. A. Khatavakar, A. K. Mandave, D. D. Baviskar, and S. L. Shinde, Int. Res. J. Eng. Technol. 5, 3791 (2018).

22. W. J. Cho and I. J. Shon, Korean J. Met. Mater. 56, 658 (2018).

23. A. El-Tantawy, W. M. Daoush, and A. E. El-Nikhaily, J. Exp. Nanosci. 13, 174 (2018).

24. J. L. Li, Y. C. Xiong, X. D. Wang, S. J. Yan, C. Yang, W.W. He, J. Z. Chen, S. Q. Wang, X. Y. Zhang, and S. L. Dai, Mater. Sci. Eng. A 626, 400 (2015).

25. M. Cao, D. B. Xiong, Z. Tan, G. Ji, B. A. Ahmadi, Q. Guo, G. Fan, C. Guo, Z. Li, and D. Zhang, Carbon 117, 65 (2017).

26. R. Jiang, X. Zhou, Q. Fang, and Z. Liu, Mater. Sci. Eng. A 654, 124 (2016).

27. M. Wang, L. D. Wang, J. Sheng, Z. Y. Yang, Z. D. Shi, Y. P. Zhu, J. Li, and W. D. Fei, J. Alloy. Compd. 798, 403 (2019).

28. Z. Yang, L. Wang, Z. Sji, M. Wang, Y. Cui, B. Wei, S. Xu, Y. Zhu, and W. Fei, Carbon 127, 329 (2018).

29. A. Naseer, F. Ahmad, M. Aslam, B. H. Guan, W. S, W. Harun, N. Muhammad, M. R. Raza, and R. M. German, Mater. Manuf. Process. 34, 957 (2019).
30. S. R. Kawk, T. A. Ring, and B. S. Choi, J. Ind. Eng. Chem. 70, 484 (2019).

31. C. Gautam, D. Chakravarty, A. Gautam, C. S. Tiwary, C. F. Woellner, V. J. K. Mishra, N. Ahmad, S. Ozden, S. Jose, S. Biradar, R. Vajtai, R. Trivedi, D. S. Galvao, and P. M. Ajayan, ACS Omega 3, 6013 (2018).

32. L. M. Guiney, N. D. Mansukhani, A. E. Jakus, S. G. Wallace, R. N. Shah, and M. C. Hersam, Nano Lett. 18, 3488 (2018).

33. J. Yin, X. Li, J. Zhou, and W. Guo, Nano Lett. 13, 3232 (2013).

34. S. Chatterjee, M. J. Kim, D. N. Zakhrov, S. M. Kim, E. A. Stach, B. Maruyama, and L. G. Sneddon, Chem. Mater. 24, 2872 (2012).

35. Q. Fang, Y. Shen, and B. Chen, Chem. Eng. J. 264, 753 (2015).

36. R. M. German, Crit. Rev. Solid State Mater. Sci. 35, 263 (2010).

37. S. A. McDonald, C. Holzner, E. M. Lauridsen, P. Reischig, A. P. Merkle, and P. J. Withers, Sci. Rep. 7, 1 (2017).

38. S. Joshi, D. Ecija, R. Koitz, M. Iammuzzi, A. P. Seitsonen, J. Hutter, H. Sachdev, S. Vijayaraghavan, F. Bischoff, K. Seufert, J. V. Barth, and W. Auwarter, Nano lett. 12, 5821 (2012).

39. J. C. Koepke, J. D. Wood, Y. Chen, S. W. Schucker, X. Liu, N. N. Chang, L. Niwnhaus, J. W. Do, E. A. Carrion, J. Hewaparakrama, A. Rangarajan, I. Datye, R. Mehta, R. T. Haasch, M. Gruebele, G. S. Girolami, E. Pop, and J. W. Lyding, Chem. Mater. 28, 4169 (2016).

40. K. Chakrabarty, I. Arnold, and S. A. Catledge, J. Vac. Sci. Technol. A 37, 061507-1 (2019).

41. A. F. Khan, E. P. Randviir, D. A. C. Brownson, X. Ji, G. C. Smith, and C. E. Banks, Electroanal. 29, 622 (2017). 